\title{
Longitudinal stent elongation or shortening after deployment in the coronary arteries: which is dominant?
}

\author{
Magdy Algowhary *i and Mohammed Aboel-Kassem F. Abdelmegid
}

\begin{abstract}
Background: Stent manufacturers always record stent shortening data while they do not record stent elongation data. The aim of this study is to identify both stent shortening and elongation occurring after deployment in the coronary arteries and know their percentage.

Results: The length of coronary stents was measured by intravascular ultrasound (IVUS) by (1) edge-to-edge (E-E) length, measured from the appearance of the first distal strut to the last proximal strut, and (2) area-to-area (A-A) length, measured from the first distal struts seen at more than one IVUS quadrant to the last proximal struts seen at more than one IVUS quadrant. Stent shortening was defined as both E-E and A-A lengths were shorter than the manufacturer box-stated length (shortened group). Stent elongation was defined as both E-E and A-A lengths were longer than the manufacturer box-stated length (elongated group), otherwise unchanged group. Consecutive 102 stents deployed in ischemic patients were included. Stent elongation was detected in $67.6 \%$ (69 stents), and shortening was detected in $15.7 \%$ (16 stents), while unchanged stents were detected in $16.7 \%$ (17 stents). Although the 3 groups had similar box-stated length and predicted foreshortened length, they had significantly different measurements by IVUS, $p<0.001$ for each comparison. Differences from box-stated length were $1.9 \pm 1.4 \mathrm{~mm},-1.4 \pm$ $0.4 \mathrm{~mm}$, and $0.4 \pm 0.3 \mathrm{~mm}$, respectively, $p<0.001$. The elongated group had significantly longer differences from the corresponding box-stated and predicted foreshortened lengths, while the shortened group had significantly shorter differences from the corresponding box-stated length and similar foreshortened length. By multinomial regression analysis, the plaque-media area and stent deployment pressure were the independent predictors of the stent length groups, $p=0.015$ and $p=0.026$, respectively.

Conclusions: Change in stent length is not only shortening - as mentioned in the manufacturer documents—but also stent elongation. Stent elongation is dominant, and the most important predictors of longitudinal stent changes are plaque-media area and stent deployment pressure.
\end{abstract}

Keywords: IVUS, Stent length, Stent elongation and shortening

\section{Background}

Coronary stenting is an important tool in the management of coronary artery disease. Understanding stent geometry is essential to treat different coronary lesions. The researchers studied stent diameter and found that the minimal stent diameter measured by intracoronary

\footnotetext{
* Correspondence: magdyalgowhary@aun.edu.eg

Department of Cardiovascular Medicine, Assiut University Heart Hospital, Faculty of Medicine, Assiut University, Asyut 71515, Egypt
}

ultrasound (IVUS) was significantly smaller than that predicted in the manufacturers' compliance charts, and these differences were independent of stent manufacturers, deployment pressure, or stent length $[1,2]$ but may be related to vessel calcium [3]. The longitudinal stent dimension is a subject for further studies. Stent foreshortening defined as the difference between the desired and the actual stent length after deployment is a part of these studies. Cases with radiologic overt stent
Springer Open

(c) The Author(s). 2021 Open Access This article is licensed under a Creative Commons Attribution 4.0 International License, which permits use, sharing, adaptation, distribution and reproduction in any medium or format, as long as you give appropriate credit to the original author(s) and the source, provide a link to the Creative Commons licence, and indicate if changes were made. The images or other third party material in this article are included in the article's Creative Commons licence, unless indicated otherwise in a credit line to the material. If material is not included in the article's Creative Commons licence and your intended use is not permitted by statutory regulation or exceeds the permitted use, you will need to obtain permission directly from the copyright holder. To view a copy of this licence, visit http://creativecommons.org/licenses/by/4.0/. 
compression and elongation after deployment are reported and termed longitudinal stent deformation (LSD) [4]. A variety of mechanisms are responsible for LSD. All of them are mechanical in origin such as the impact of guiding catheter tip or following passage of catheters, guidewire, post-dilatation balloon, embolic protection devices, and IVUS catheters [5]. In the past, it was reported after deployment of coil stents such as Wiktor stent $[6,7]$ and more recently after deployment of Promus, Xience, and Endeavor stents [8-14]. LSD affects coronary blood flow leading to stent thrombosis [5], target lesion failure [14], and even death [7]. Of note, it is not evident in the majority of cases [5, 9]; however, stent shortening and elongation are frequently seen but at a less magnitude. Stent shortening is evident in selfexpandable stents so that the stent with enough length should be used to cover the whole lesion site. It is also evident in balloon-mounted stents [15]. On the other side, stent elongation is recorded. Although in recent trials using IVUS examination stent elongation could be seen after deployment of balloon-mounted stents [16], still stent foreshortening is the only longitudinal stent change mentioned in stent manufacturer documents.

The aim of this study is to confirm the presence of stent elongation and/or shortening and its percentage in reality after deployment of balloon-mounted stents in coronary lesions providing that there is no LSD problem detected by both angiographic and IVUS examinations.

\section{Methods}

\section{Study population}

Consecutive patients with stable, unstable angina pectoris and myocardial infarction due to de novo coronary artery disease were included in this study. All patients who underwent a successful IVUS-guided percutaneous coronary intervention were included in this study. The study was conducted on real-world patients after a written informed consent was taken from every patient who underwent cardiac catheterization. All procedures performed in studies involving human participants were in accordance with the ethical standards of the Helsinki Declaration. The lesions were selected based on angiographic examination. To avoid incorrect stent length measurements, lesions were included if they had no acute angulation, no tortuosity, no ectasia, and no heavy calcification. Moreover, lesion type C, bifurcation lesion, small vessel disease (reference vessel size less than $2.0 \mathrm{~mm}$ ), and ostial lesion were excluded from the analysis. Lesions located at the side branch should be totally covered by the stent away from its ostium. Both drugeluting stents (DES) and bare-metal stents (BMS) were included according to the operator's decision. Six types of stents were used: Multilink (Abbott, IL, USA), Integrity (Medtronic, MN, USA), Commander (Alvimedica,
IS, Turkey), Promus (everolimus-eluting stent, Boston, MA, USA), Resolute (Zotarolimus eluting stent, Medtronic, MN, USA), and Cre8 (sirolimus-eluting stent, CID, VC, Italy). Small stents, $<3.0 \mathrm{~mm}$ in diameter, were not included in the analysis. Patients with a two-vessel disease were also included as long as one stent per lesion was used. Patients were excluded when the lesions were treated by two overlapped stents, in-stent restenosis, poor IVUS image quality, manual pullback, non-uniform or interrupted IVUS pullback, and cases with radiologic longitudinal stent deformation or fracture. All patients gave informed consent and that the authors have conformed to the institutional guidelines.

On the basis of diagnostic coronary angiography, patients underwent percutaneous coronary intervention if one or more major coronary arteries had a stenosis of at least $70 \%$ and were suitable for revascularization. Antiplatelets and heparin were administered before the procedures. Balloon-mounted stents were deployed directly or after balloon dilatation. No exclusion was made for stent type, strut thickness, stent recoil, stent metal/artery ratio, or the number of strut connectors. Coronary stenting was guided by IVUS examination before and after stenting. If incomplete stent expansion/malapposition was detected, further balloon dilatation was done to achieve optimal stenting results.

\section{IVUS procedure and analysis}

Examination was performed using a 2.5-F IVUS catheter operating on a frequency of $40 \mathrm{MHz}$ after administration of intracoronary nitrates, $200 \mathrm{mcg}$. The transducer was positioned in the distal vessel, at least $10 \mathrm{~mm}$ distal to the stent, and withdrawn at a rate of $0.5-1.0 \mathrm{~mm} / \mathrm{s}$ with the use of a motor drive (CardioVascular Imaging System ClearView Ultra, CVIS, Boston Scientific, Fremont, CA, USA) to the aorto-ostial junction. On a computer screen, manual planimetry was performed to measure the external elastic membrane $(\mathrm{EEM}=$ vessel area $(\mathrm{VA}))$ and lumen areas (LA) in all frames. Since the IVUS catheter may not pass through the center of the stent in all examinations, the transverse plane of stent edges may not identically the same as the transverse plane of the vessel. Cases with study images that had an oval-shaped image or distorted image were not included. Moreover, to minimize the effect of this disposition on the accuracy of stent length measurements, stent length was derived by 3 methods: (1) edge-to-edge (E-E) stent length which was the distance measured at the long axis from the first distal frame with the first stent strut located at one quadrant seen at the short axis to the proximal frame with the last stent strut located at one quadrant, (2) area-to-area (A-A) stent length which was the distance measured at the long axis from the first distal frame with the first stent struts located at two or more quadrants 
seen at the short axis to the proximal frame with the last stent struts located at two or more quadrants, and (3) average stent length: [(E-E) length + (A-A) length]/2. The distance located between the start of E-E length to the A-A length on both ends was not an exclusion criterion. Details of the definitions and measurements of E$\mathrm{E}, \mathrm{A}-\mathrm{A}$, and average lengths used as parameters for the stent length were explained before by the work of Dvir et al. published in 2014 [16]. Longitudinal stent length was considered as follows: (1) elongated if both E-E length and A-A length were longer than manufacturer's box-stated length, (2) shortened if both E-E length and A-A length were shorter than the manufacturer's boxstated length, and (3) unchanged if it was neither 1 nor 2.

\section{Statistical analysis}

Categorical variables are presented as frequencies. Continuous variables are reported as mean \pm SD for normally distributed variables and median [interquartile range (IQR)] for variables without a normal distribution pattern. The chi-square with Fisher's exact tests were used for comparisons of categorical variables. For normally distributed variables, the $T$ tests (paired and independent samples) were used to measure equality of the means between 2 groups. One-way ANOVA was used for group comparison, and the Bonferroni and Tamhane methods were used for post hoc comparisons. For nonparametric comparisons, the Wilcoxon, Mann-Whitney, and Kruskal-Wallis tests were used. For correlations, the Pearson and Spearman tests were used. To identify the predictors of the stent length groups (shortened, unchanged, and elongated stents), the multinomial logistic regression analysis with stepwise forward entry method was used. The following variables were entered in the model: smoking, ejection fraction, deployment pressure groups, DES/BMS, deployed stents, stent diameter, manufacturer predicted foreshortened stent length, lesion length, minimal lumen diameter, lesion plaque type by IVUS, distal edge plaque type by IVUS, reference LA by IVUS, lesion VA, lesion LA, lesion plaque-media area, proximal edge VA, proximal edge LA, proximal edge plaque-media area, distal edge VA, and distal edge plaque-media area. All tests were performed by using the SPSS package version 25 (SPSS Inc., Chicago, IL, USA). The statistical tests were two-sided, and $p<0.05$ was considered statistically significant.

\section{Results}

Consecutive 102 balloon-mounted coronary stents were used to treat ischemic patients; their age ranged from 40 to 84 years old; $84.3 \%$ were males (86 patients), $64.7 \%$ were hyperlipidemic (66 patients), $62.7 \%$ were hypertensive (64 patients), 52.9\% were smokers
(54 patients), and $33.3 \%$ were diabetic (34 patients). Tables 1 and 2 show the patients' clinical, angiographic, and IVUS data by stent groups. The elongated stents represent $67.6 \% \quad(69$ stents $)$, the shortened stents represent $15.7 \%$ (16 stents), and the unchanged stents (similar to manufacturer stent boxstated length) represent 16.7\% (17 stents). Apart from smoking, stent type (DES and BMS), and stent diameter, the 3 stent groups have no statistically significant differences regarding clinical, angiographic, and stenting data. Deployed stents, stent length (from 8 to $38 \mathrm{~mm}$ ), stent metal/artery ratio, stent recoil percentage, strut thickness, manufacturer stent box-stated length, and stent foreshortening are not significantly different while IVUS data shows mixed parameters (Tables 1 and 3). Reference VA, reference LA, proximal LA, distal LA, eccentric lesion plaque, and plaque characters at both stent edges are not significantly different. Lesion plaque-media area, proximal plaque-media area, and plaque characters at the lesion site tend to be significantly different. The 3 groups have significantly different measurements regarding proximal VA, lesion VA, lesion LA, distal VA, and distal plaque-media area. By post hoc analysis, the elongated stent group has a significantly smaller vessel area than the unchanged stent group at the lesion site, $p=0.003$; proximal site, $p=0.01$; and distal site, $p<$ 0.001 . Also, it has a significantly smaller lumen area at the lesion site, $p=0.01$, and a smaller plaque-media area at the distal site, $p<0.001$.

The stent box-stated length is highly correlated with IVUS measurements of stent lengths, for all correlations $r=0.96$ and $p<0.001$. Manufacturer stent length data including box-stated length and predicted foreshortened length are comparable among the 3 groups (Table 4) while IVUS stent length measurements regarding E-E and A-A lengths tend to be different, and the average length is significantly different, $p=0.01$. The median average stent length is significantly longer in the elongated group than in both the shortened and the unchanged groups, $p=0.03$ and $p=0.01$, respectively. Moreover, the differences in length between IVUS measurements (E-E, A-A, and average lengths) and manufacturer lengths (box-stated length and predicted foreshortened lengths) are significant among the 3 groups, $p<0.001$ for each comparison (Fig. 1). The difference between E-E length and box-stated length is significantly longer in the elongated group than in both the shortened and unchanged groups, $p<0.001$ and $p=0.004$, respectively. Also, it is significantly shorter in the shortened group than in the unchanged group, $p=0.008$. Similarly, the difference between A-A length and the boxstated length is significantly longer in the elongated group than in both the shortened and unchanged 
Table 1 Baseline characteristics by groups

\begin{tabular}{|c|c|c|c|c|c|}
\hline & & $\begin{array}{l}\text { Elongated stents } \\
(n=69,67.6 \%)\end{array}$ & $\begin{array}{l}\text { Shortened stents } \\
(n=16,15.7 \%)\end{array}$ & $\begin{array}{l}\text { Unchanged stents } \\
(n=17,16.7 \%)\end{array}$ & $p$ value \\
\hline Age, years & & $65.6 \pm 10.0$ & $67.6 \pm 10$ & $64.8 \pm 11.6$ & 0.72 \\
\hline Males & & 57 (82.6\%) & $14(87.5 \%)$ & 15 (88.2\%) & 0.92 \\
\hline Smoking & & $30(43.5 \%)$ & $12(75 \%)$ & $12(70.6 \%)$ & 0.043 \\
\hline Hypertension & & $42(60.9 \%)$ & $12(75 \%)$ & $10(58.8 \%)$ & 0.77 \\
\hline DM & & $22(31.9 \%)$ & $8(50 \%)$ & $4(23.5 \%)$ & 0.37 \\
\hline Dyslipidemia & & $45(65.2 \%)$ & $11(68.8 \%)$ & $10(58.8 \%)$ & 0.8 \\
\hline Family history & & $7(10.1 \%)$ & $4(25 \%)$ & $3(17.6 \%)$ & 0.28 \\
\hline \multirow[t]{4}{*}{ Clinical presentation } & & & & & 0.27 \\
\hline & AP & $29(42 \%)$ & 7 (43.8\%) & $6(35.3 \%)$ & \\
\hline & UAP & $20(29 \%)$ & $7(43.8 \%)$ & $3(17.6 \%)$ & \\
\hline & $\mathrm{AMI}$ & $20(29 \%)$ & $2(12.5 \%)$ & $8(47.1 \%)$ & \\
\hline Statin & & 41 (59.4\%) & $9(56.3 \%)$ & 7 (41.2\%) & 0.27 \\
\hline Beta blockers & & 17 (24.6\%) & $7(43.8 \%)$ & $5(29.4 \%)$ & 0.39 \\
\hline Calcium antagonists & & $26(37.7 \%)$ & $9(56.3 \%)$ & $7(41.2 \%)$ & 0.65 \\
\hline ACE-I & & $16(23.2 \%)$ & $5(31.3 \%)$ & $4(23.5 \%)$ & 0.94 \\
\hline ARB & & $20(29 \%)$ & $4(25 \%)$ & $8(47.1 \%)$ & 0.28 \\
\hline EF & & $62.9 \pm 11.6$ & $64.0 \pm 13.7$ & $55.0 \pm 14.7$ & 0.061 \\
\hline Cholesterol, mg/dL & & $189.5 \pm 32.6$ & $192.7 \pm 39.8$ & $189.4 \pm 47.3$ & 0.95 \\
\hline HDL-cholesterol, mg/dL & & $49.4 \pm 12.6$ & $47.4 \pm 12.6$ & $45.3 \pm 18.3$ & 0.61 \\
\hline LDL-cholesterol, mg/dL & & $121.9 \pm 31.1$ & $116.2 \pm 13.4$ & $114.8 \pm 26.3$ & 0.85 \\
\hline \multicolumn{6}{|l|}{ Angiographic data: } \\
\hline \multirow[t]{4}{*}{ Stented vessel } & & & & & 0.37 \\
\hline & LAD & $40(58 \%)$ & $11(68.8 \%)$ & $8(47.1 \%)$ & \\
\hline & LCX & $13(18.8 \%)$ & $4(25 \%)$ & $3(17.6 \%)$ & \\
\hline & $\mathrm{RCA}$ & $16(23.2 \%)$ & $1(6.3 \%)$ & $6(35.3 \%)$ & \\
\hline \multirow[t]{4}{*}{ ACC/AHA lesion type } & & & & & 0.45 \\
\hline & A & $31(44.9 \%)$ & $8(50 \%)$ & $9(52.9 \%)$ & \\
\hline & B & $31(44.9 \%)$ & $8(50 \%)$ & $8(47.1 \%)$ & \\
\hline & $C$ & $7(10.1 \%)$ & 0 & 0 & \\
\hline Lesion length, mm & & $11.3 \pm 6.4$ & $9.4 \pm 3.8$ & $8.8 \pm 3.2$ & 0.18 \\
\hline Reference diameter, mm & & $3.1 \pm 0.6$ & $3.1 \pm 0.7$ & $3.3 \pm 0.7$ & 0.45 \\
\hline MLD, mm & & $0.8 \pm 0.3$ & $0.8 \pm 0.3$ & $1.0 \pm 0.2$ & 0.15 \\
\hline DS\% & & $74.1 \pm 16.3$ & $71.2 \pm 14.9$ & $70.9 \pm 6.9$ & 0.65 \\
\hline Deployment pressure, atm & & $16.7 \pm 3.2$ & $15.1 \pm 3.4$ & $16.1 \pm 2.8$ & 0.19 \\
\hline High pressure stenting, $>16 \mathrm{~atm}$ & & 49 (71\%) & $7(43.8 \%)$ & $10(58.8 \%)$ & 0.105 \\
\hline Post-stent baloon dilatation & & $20(29 \%)$ & $2(12.5 \%)$ & $4(23.5 \%)$ & 0.49 \\
\hline \multicolumn{6}{|l|}{ IVUS data: } \\
\hline Reference VA, mm2 & & $15.4 \pm 3.8$ & $14.9 \pm 3.3$ & $17.4 \pm 4.6$ & 0.26 \\
\hline Reference LA, mm2 & & $9.3 \pm 2.2$ & $8.9 \pm 2.6$ & $10.8 \pm 2.8$ & 0.14 \\
\hline Proximal site VA, mm2 & & $16.6 \pm 5.0^{*}$ & $17.0 \pm 4.3$ & $21.7 \pm 4.8$ & 0.02 \\
\hline Proximal site LA, mm2 & & $8.7 \pm 3.2$ & $9.0 \pm 2.6$ & $11.0 \pm 4.3$ & 0.15 \\
\hline Proximal site PMA, mm2 & & $7.9 \pm 3.2$ & $8.0 \pm 2.8$ & $10.7 \pm 4.3$ & 0.064 \\
\hline Lesion VA, mm2 & & $13.2 \pm 4.0^{*}$ & $14.3 \pm 4.0$ & $17.6 \pm 5.0$ & 0.004 \\
\hline
\end{tabular}


Table 1 Baseline characteristics by groups (Continued)

\begin{tabular}{|c|c|c|c|c|}
\hline & $\begin{array}{l}\text { Elongated stents } \\
(n=69,67.6 \%)\end{array}$ & $\begin{array}{l}\text { Shortened stents } \\
(n=16,15.7 \%)\end{array}$ & $\begin{array}{l}\text { Unchanged stents } \\
(n=17,16.7 \%)\end{array}$ & $p$ value \\
\hline Lesion LA, mm2 & $4.0 \pm 1.9^{*}$ & $4.4 \pm 1.9$ & $5.7 \pm 2.0$ & 0.016 \\
\hline Lesion PMA, mm2 & $9.2 \pm 3.4$ & $9.9 \pm 3.3$ & $11.9 \pm 5.2$ & 0.063 \\
\hline Distal site VA, mm2 & $10.8 \pm 3.4^{*}$ & $12.0 \pm 3.9$ & $15.6 \pm 3.2$ & $<0.001$ \\
\hline Distal site LA, mm2 & $6.1 \pm 2.1$ & $6.5 \pm 2.0$ & $6.9 \pm 2.2$ & 0.45 \\
\hline Distal site PMA, mm2 & $4.7 \pm 2.4^{*}$ & $5.5 \pm 2.8$ & $8.8 \pm 2.9$ & $<0.001$ \\
\hline
\end{tabular}

Data provided as mean \pm SD or number (\%)

ACC/AHA American College of Cardiology and American Heart Association, ACE-I angiotensin converting enzyme inhibitors, $A M I$ acute myocardial infacrtion, $A P$ stable angina pectoris, $A R B$ angiotensin receptor blockers, CRP C-reactive protein, DES drug-eluting stent, DM diabetes mellitus, DS\% diameter stenosis percentage, $E F$ ejection fraction, $H D L-C$ high density lipoprotein cholesterol, IVUS intravascular ultrasound, $L A$ lumen area, $L A D$ left anterior descending artery, $L C X$ left circumflex artery, $L D L-C$ low density lipoprotein cholesterol, $M L D$ minimal lumen diameter, $P M A$ plaque-media area, $R C A$ right coronary artery, $U A P$ unstable angina pectoris, VA vessel area

${ }^{*} p<0.05$, compared to unchanged stents

groups, $p<0.001$ for each comparison; consequently, the median difference between the average IVUS length and the box-stated length is significantly longer in the elongated group than in both the shortened and unchanged groups, $p<0.001$ for each comparison, and significantly shorter in the shortened group than unchanged group, $p=0.001$. The difference between E-E length and predicted foreshortened stent length in the elongated group is significantly longer than the difference in the shortened and in unchanged groups, $p<0.001$ and $p=0.02$, respectively. Similarly, the difference between A-A length and predicted foreshortened stent length is significantly longer in the elongated group than the others, $p<0.001$ and $p=0.004$, respectively; consequently, the median difference between the average length and the predicted foreshortened stent length is significantly longer in the elongated group than in the shortened and unchanged groups, $p<0.001$ for each comparison, and it is significantly shorter in the shortened group than in the unchanged group, $p=0.001$.
Table 5 shows the measurements of the stent length by IVUS compared to corresponding manufacturer boxstated stent length. In the elongated stent group, the E$\mathrm{E}, \mathrm{A}-\mathrm{A}$, and average lengths are significantly longer than their corresponding box-stated stent length, $p<0.001$ for each comparison. Also, in the shortened stent group, they are significantly shorter than their corresponding box-stated measurements, $p=0.05, p=0.04$, and $p=0.001$, respectively.

Table 6 shows the measurements of stent length by IVUS compared to the manufacturer-predicted foreshortened stent length. In the elongated stent group, the E-E, $\mathrm{A}-\mathrm{A}$, and average lengths are significantly longer than their corresponding predicted foreshortened stent length, $p<0.001$ for each comparison, while in shortened stent group, the E-E, A-A, and average lengths are comparable with their corresponding predicted foreshortened stent length.

The multivariate analysis model selects the stent deployment pressure groups, $p=0.026$, and plaque-media

Table 2 Stent types and characters by groups

\begin{tabular}{|c|c|c|c|c|}
\hline & $\begin{array}{l}\text { Elongated stents } \\
(n=69,67.6 \%)\end{array}$ & $\begin{array}{l}\text { Shortened stents } \\
(n=16,15.7 \%)\end{array}$ & $\begin{array}{l}\text { Unchanged stents } \\
(n=17,16.7 \%)\end{array}$ & $p$ value \\
\hline Stent type, \% & & & & 0.01 \\
\hline DES & $38(55.1 \%)$ & $4(25 \%)$ & $3(17.6 \%)$ & \\
\hline BMS & $31(44.9 \%)$ & $12(75 \%)$ & $14(82.4 \%)$ & \\
\hline Stent box-stated length, $\mathrm{mm}$ & & & & 0.34 \\
\hline Less than $20 \mathrm{~mm}$ & $45(65.2 \%)$ & $10(62.5 \%)$ & $14(82.4 \%)$ & \\
\hline More than $20 \mathrm{~mm}$ & $24(34.8 \%)$ & $6(37.5 \%)$ & $3(17.6 \%)$ & \\
\hline Stent diameter, $\mathrm{mm}$ & $3.0(3.0-3.0)$ & $3.0(3.0-4.0)$ & $4.0(3.0-4.0)^{*}$ & 0.01 \\
\hline Stent strut thickness, micro & $81.0(81.0-91.0)$ & $81.0(81.0-88.5)$ & $81.0(81.0-86.0)$ & 0.69 \\
\hline Stent metal/artery ratio & $19.0(14.1-19.9)$ & $19.0(19.0-19.9)$ & $19.0(19.0-19.5)$ & 0.81 \\
\hline Stent recoil (\%) & $4.0(3.0-4.9)$ & $4.0(3.0-4.0)$ & $4.0(3.5-4.0)$ & 0.94 \\
\hline
\end{tabular}

Data provided as number (\%) or median (IQR) $B M S$ bare-metal stents, DES drug-eluting stents ${ }^{*} p=0.002$, compared to the elongated group 
Table 3 IVUS plaque-media type by groups

\begin{tabular}{|c|c|c|c|c|}
\hline & Elongated stents $(n=69,67.6 \%)$ & Shortened stents ( $n=16,15.7 \%)$ & Unchanged stents ( $n=17,16.7 \%)$ & $p$ value \\
\hline At proximal edge & & & & 0.39 \\
\hline Soft & $14(20.3 \%)$ & $3(18.8 \%)$ & $5(29.4 \%)$ & \\
\hline Mixed & $21(30.4 \%)$ & $5(31.3 \%)$ & $5(29.4 \%)$ & \\
\hline Hard & $4(5.8 \%)$ & $1(6.3 \%)$ & $1(5.9 \%)$ & \\
\hline Superficial calcification & $19(27.5 \%)$ & $3(18.8 \%)$ & $3(17.6 \%)$ & \\
\hline Deep calcification & $11(15.9 \%)$ & $4(25 \%)$ & $3(17.6 \%)$ & \\
\hline At lesion site & & & & 0.06 \\
\hline Soft & $13(18.8 \%)$ & $1(6.3 \%)$ & $2(11.8 \%)$ & \\
\hline Mixed & $15(21.7 \%)$ & $5(31.3 \%)$ & $5(29.4 \%)$ & \\
\hline Hard & $6(8.7 \%)$ & $5(31.3 \%)$ & $2(11.8 \%)$ & \\
\hline Superficial calcification & $15(21.7 \%)$ & $3(18.8 \%)$ & $2(11.8 \%)$ & \\
\hline Deep calcification & $20(29 \%)$ & $2(12.5 \%)$ & $6(35.3 \%)$ & \\
\hline Eccentric lesion plaque & & & & 0.98 \\
\hline Yes & $32(46.4 \%)$ & $9(56.3 \%)$ & $6(35.3 \%)$ & \\
\hline At distal edge & & & & 0.11 \\
\hline Soft & $17(24.6 \%)$ & $3(18.8 \%)$ & $2(11.8 \%)$ & \\
\hline Mixed & $10(14.5 \%)$ & $5(31.3 \%)$ & $5(29.4 \%)$ & \\
\hline Hard & $5(7.2 \%)$ & $2(12.5 \%)$ & $1(5.9 \%)$ & \\
\hline Superficial calcification & $22(31.9 \%)$ & $3(18.8 \%)$ & $5(29.4 \%)$ & \\
\hline Deep calcification & $15(21.7 \%)$ & $3(18.8 \%)$ & $4(23.5 \%)$ & \\
\hline
\end{tabular}

Data provided as number (\%)

IVUS intravascular ultrasound

area, $p=0.015$, as the most significant independent predictors of stent length groups with a significant final fitting model ( -2 log-likelihood ratio $49.28, p=0.003)$ and $56.3 \%$ correct classification. The difference of stent length between IVUS measurement and manufacturer length is correlated directly with deployment pressure and inversely with plaque-media area (Figs. 2 and 3).

\section{Discussion}

The chief findings of this study were the presence of 3 forms of stent length after deployment in coronary artery lesions: elongated stents, shortened stents, and unchanged stents. Compared with the manufacturer boxstated length, $67.6 \%$ of the stents showed stent elongation without LSD confirmed by angiography and IVUS examination [10]. The rest of the stents were either unchanged stents $(16.7 \%)$ which had similar manufacturer stent length data or shortened stents (15.7\%) which had only similar manufacturer foreshortened stent length data. Stent elongation was the dominant finding in contrary to manufacturer data which stressed only on 2 forms: nominal and foreshortened stent lengths. This elongation was associated with stent deployment pressure and the amount of lesion plaque-media area.

The real-life change in stent length varies from $-1.4 \mathrm{~mm}$ (shortening) to $1.9 \mathrm{~mm}$ (elongation). Stent elongation was seen in $67.7 \%$ of the stents (69 stents) while shortening was seen in $15.7 \%$ of the stents (16 stents); therefore, occurence of stent elongation was 4.3 times as much as stent shortening. Not only the incidence but also the quantity was greatly different. The median stent elongation exceeded $1.0 \mathrm{~mm}$ [difference of average IVUS stent length and box-stated stent length = $1.3 \mathrm{~mm}(0.7-2.2)]$, while the median shortening was very minimal $\{-0.5 \mathrm{~mm}[(-1.1)-(-0.4)]\}$. If the overall median difference was not great, we noticed that $19.6 \%$ of studied stents, 20 stents, exceeded $2 \mathrm{~mm}$ and reached $5.0 \mathrm{~mm}$ in some stents, while shortening of more than $1 \mathrm{~mm}$ was not seen except in $3.92 \%$ of all stents, 4 stents. Of course, this elongation was of concern though it was not mentioned by the stent manufacturers.

Nevertheless, elongated stents would have either beneficial or drawback effects. The possible beneficial effect would come from a complete covering of the lesion site giving good long-term results regarding restenosis. Also, the stent edges would be deployed in normal or less diseased proximal and distal reference segments decreasing the chance of stent edge restenosis. On the opposite side, the possible drawback would result from stent malapposition at the stent edge especially at the proximal reference segment which would be larger than the distal segment. If optimization would not be performed, 
Table 4 IVUS and manufacturer stent lengths by groups

\begin{tabular}{|c|c|c|c|c|}
\hline & $\begin{array}{l}\text { Elongated stents } \\
(n=69,67.6 \%)\end{array}$ & $\begin{array}{l}\text { Shortened stents } \\
(n=16,15.7 \%)\end{array}$ & $\begin{array}{l}\text { Unchanged stents } \\
(n=17,16.7 \%)\end{array}$ & $p$ value \\
\hline \multicolumn{5}{|l|}{ Manufacturer stent length measurements } \\
\hline Box-stated stent length, mm & $19.3 \pm 5.7$ & $19.9 \pm 4.7$ & $17.7 \pm 6.4$ & 0.49 \\
\hline Predicted forshortened stent length, $\mathrm{mm}$ & $18.4 \pm 4.9$ & $19.5 \pm 4.7$ & $16.0 \pm 3.8$ & 0.1 \\
\hline \multicolumn{5}{|l|}{ IVUS stent length measurements } \\
\hline (E-E) stent length, mm & $21.2 \pm 6.2$ & $18.5 \pm 4.3$ & $18.1 \pm 6.5$ & 0.08 \\
\hline (A-A) stent length, mm & $20.7 \pm 6.3$ & $18.2 \pm 4.4$ & $17.2 \pm 6.6$ & 0.06 \\
\hline Average IVUS stent length, mm & $19.7(16.2-24.3)^{*}$ & $17.4(14.7-22.7)$ & $17.7(14.7-18.3)$ & 0.01 \\
\hline \multicolumn{5}{|l|}{ Stent length differences (IVUS-manufacturer) } \\
\hline (E-E) stent length - box-stated stent length, $\mathrm{mm}$ & $1.9 \pm 1.4^{*}$ & $(-) 1.4 \pm 0.4^{\dagger}$ & $0.4 \pm 0.3$ & $<0.001$ \\
\hline (A-A) stent length - box-stated stent length, mm & $1.4 \pm 1.3^{*}$ & $(-) 1.8 \pm 0.3$ & $(-) 0.5 \pm 0.4$ & $<0.001$ \\
\hline Average IVUS stent length - box-stated stent length, mm & $1.3(0.7-2.2)^{*}$ & $(-) 0.5[(-) 1.1-(-) 0.4]^{\dagger}$ & $(-) 0.1[(-) 0.3-0.2]$ & $<0.001$ \\
\hline (E-E) stent length - predicted foreshortened stent length, $\mathrm{mm}$ & $1.84(1.3-2.8)^{*}$ & $0.65(0.5-1.1)$ & $(-) 0.2[(-) 0.5-0.3]$ & $<0.001$ \\
\hline (A-A) length - predicted foreshortened stent length, $\mathrm{mm}$ & $1.3(0.8-2.3)^{*}$ & $(-) 0.04[(-) 0.4-0.2]$ & $(-) 0.4[(-) 0.8-(-) 0.1]$ & $<0.001$ \\
\hline Average IVUS stent length - predicted foreshortened stent length, $\mathrm{mm}$ & $1.6(1.0-2.6)^{*}$ & $(-) 0.3[(-) 0.7-0.6]^{\dagger}$ & $0.3(0.1-0.5)$ & $<0.001$ \\
\hline
\end{tabular}

Data provided as mean \pm SD or median (IQR)

$A-A$ area-to-area length, $E-E$ edge-to-edge length, IVUS intravascular ultrasound ${ }^{*} p<0.05$, compared to both shortened and unchanged stents

${ }^{+} p<0.05$, compared to unchanged stents

stent thrombosis might occur, and consequently, myocardial infarction might happen. Moreover, an elongated stent may protrude into the nearby ostium of a side branch. On trying to deploy a stent in that nearby side branch, the protruded stent might obstruct the passage of the second stent to the side branch lesion. It might cause stent dislodgment or even embolization which would carry serious complications. This would be important in doing an intervention for a bifurcation lesion especially bifurcation of the left main coronary artery.

Although elongation was not related to the manufacture stent data (type, strut thickness, metal/artery, radial force), it was related to stent deployment pressure and plaque-media area. Of note, $92.1 \%$ of the study stents were deployed at a pressure more than $12 \mathrm{~atm}$ explaining why $67.6 \%$ of the stents were elongated. Recently, the expert consensus document of the European Association of Percutaneous Cardiovascular Intervention implies the importance of choosing stent length to cover the whole coronary lesion in order to avoid stent failure,

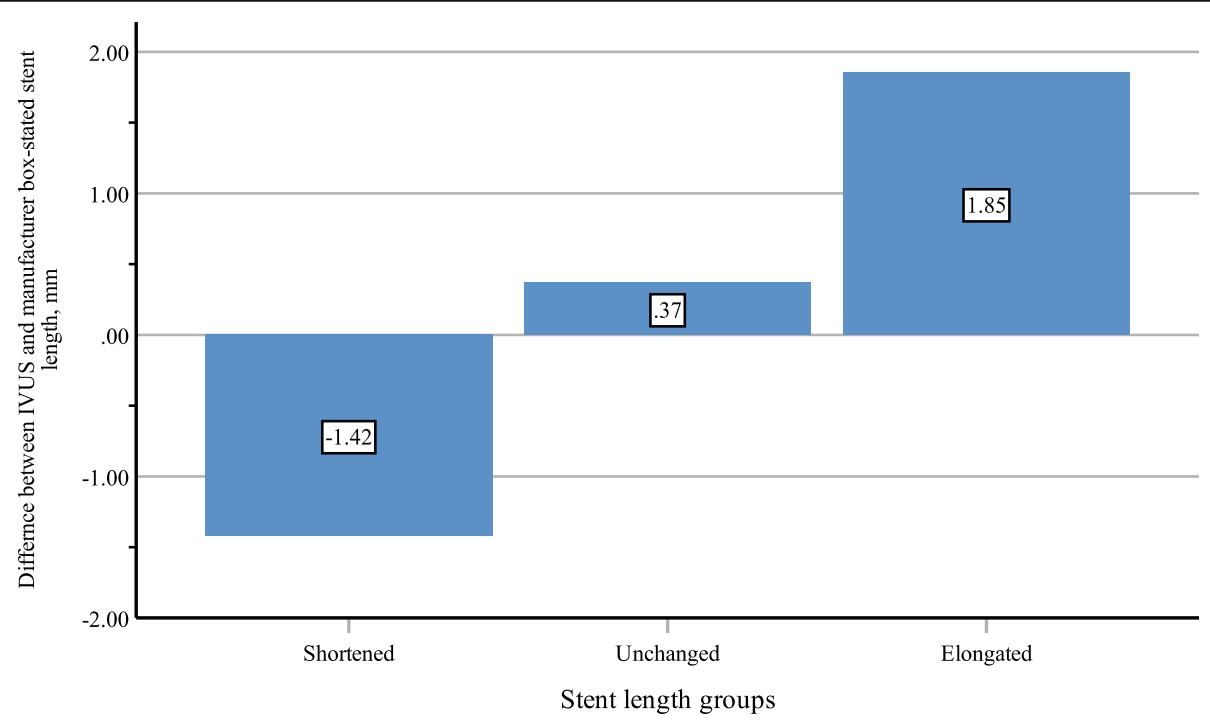

Fig. 1 Groups of stent length classified by intravascular ultrasound 
Table 5 IVUS stent lengths vs manufacturer box-stated stent length

\begin{tabular}{llllllll}
\hline & Box-stated length & E-E length & $\boldsymbol{p}$ & A-A length & $\boldsymbol{p}^{*}$ & Average IVUS length $^{\boldsymbol{p}^{\boldsymbol{\dagger}}}$ \\
\hline Elongated stent group, $\mathrm{mm}$ & $19.3 \pm 5.7$ & $21.2 \pm 6.2$ & $<0.001$ & $20.7 \pm 6.3$ & $<0.001$ & $19.7(16.2-24.3)$ & $<0.001$ \\
Shortened stent group, $\mathrm{mm}$ & $19.9 \pm 4.7$ & $18.5 \pm 4.3$ & 0.05 & $18.2 \pm 4.4$ & 0.04 & $17.4(14.7-22.7)$ & 0.001 \\
\hline
\end{tabular}

Data provided as mean $\pm \mathrm{SD}$ or median (IQR)

$A-A$ length area-to-area stent length, $E-E$ length edge-to-edge stent length, IVUS intravascular ultrasound

${ }^{*} p$ denotes A-A stent length vs box-stated stent length

${ }^{\dagger} p$ denotes average IVUS stent length vs box-stated stent length [in the elongated stent group $=19.7(16.2-24.3)$ vs 18.0 (15-23) and in the shortened stent group $=17.4(14.7-22.7)$ vs $18.0(15.8-23.8)]$

stent thrombosis and restenosis, and occurrence of major adverse cardiac events such as myocardial infarction [17]. It also encourages the avoidance of landing stent edge within an area with plaque burden $>50 \%$ to decrease the incidence of stent edge restenosis. In order to achieve full lesion coverage, we have to select ideal stent length by angiographic and other imaging modalities such as IVUS and optical coherence tomography (OCT). Knowing the manufacturer's nominal stent length is mandatory for stent length selection keeping in mind that manufacturer foreshortening data is usually minimal. It is very important to choose stent length to avoid incomplete lesion coverage with its sequels because incomplete lesion coverage reaches up to $90 \%$ of lesions as documented by near-infrared spectroscopy and IVUS (NIRS-IVUS) [18]. It may be due to inaccurate stent length selection depending on angiographically measured lesion length alone and the occurrence of stent shortening. For this reason, manufacturer data always mention nominal and foreshortening data for each stent. Nevertheless, stent elongation data is usually not mentioned though recent studies of stent length have proved its existence [16, 18-22].

Not only in vivo human studies but also in vitro studies using bench models have shown stent elongation phenomenon in the current stents. It occurs under the influence of post-dilatation [4, 20, 23, 24]. Interestingly, linear stent elongation could be seen during each step of balloon dilatation depending on balloon dilatation pressure $[23,24]$ which is similar to our finding and the direction of dilatation [20]. More stent elongation could be detected when dilatation was performed in a distal to proximal direction [20]. Regarding in vivo studies, stent elongation has been documented in both first-generation DES (Cypher and Taxus stents) and second-generation
DES (Xience V, Promus Element, and Endeavor stents) [16]. Similar to our results, the use of high deployment pressure is correlated with stent length difference. Recently, measuring the stent length by OCT after deployment in coronaries has revealed stent length elongation in series of DES (Xience series, Promus series, Ultimaster, Synergy, Integrity, and Coroflex stents) [19]. Post-balloon dilatation has been significantly associated with stent length differences too. Moreover, malapposition of the stent edge has been responsible for stent elongation after postdilatation. The use of the proximal optimization technique (post-dilatation by a suitable balloon at the proximal edge rather than from the distal to proximal dilatation) has prevented stent elongation. This technique may be useful as it may prevent stent protrusion into the left main trunk during the intervention at the proximal portion of the left anterior descending branch or left circumflex branch [21]. Masuda et al. have explained that the use of postdilatation balloon has resulted in generating longitudinal forces moving the stent longitudinally. However, proximal balloon dilatation may stop stent elongation as malapposition is usually encountered at the proximal edge [19] confirming the same in vitro results obtained recently by Sumi et al. [20]. The proximal optimization technique usually results in good stent apposition to the vessel wall preventing the stent from elongation in contrary to free stent edge with malapposition that will elongate easily. In the present study, multivariate analyses denote that deploying stent under high pressure is associated with stent elongation as it generates longitudinal forces pushing stent struts. Moreover, the presence of less plaque-media area at the lesion site and at the stent edges will allow easier longitudinal

Table 6 IVUS stent lengths vs predicted foreshortened stent length

\begin{tabular}{|c|c|c|c|c|c|c|c|}
\hline & Predicted foreshortened length & E-E length & $p$ & A-A length & $p^{*}$ & Average IVUS length & $p^{+}$ \\
\hline Elongated stent group, mm & $18.4 \pm 4.9$ & $21.2 \pm 6.2$ & $<0.001$ & $20.7 \pm 6.3$ & $<0.001$ & $19.7(16.2-24.3)$ & $<0.001$ \\
\hline Shortened stent group, mm & $19.5 \pm 4.7$ & $18.5 \pm 4.3$ & 0.19 & $18.2 \pm 4.4$ & 0.1 & $17.4(14.7-22.7)$ & 0.077 \\
\hline
\end{tabular}

Data provided as mean \pm SD or median (IQR)

$A-A$ length area-to-area stent length, $E-E$ length edge-to-edge stent length, IVUS intravascular ultrasound

${ }^{*} p$ denotes A-A stent length vs predicted foreshortened stent length

${ }^{+} p$ denotes average IVUS stent length vs predicted foreshortened stent length [in the elongated stent group $=19.7(16.2-24.3)$ vs $17.8(14.6-22.8)$ and in the shortened stent group $=17.4(14.7-22.7)$ vs $17.6(15.3-23.7)]$ 


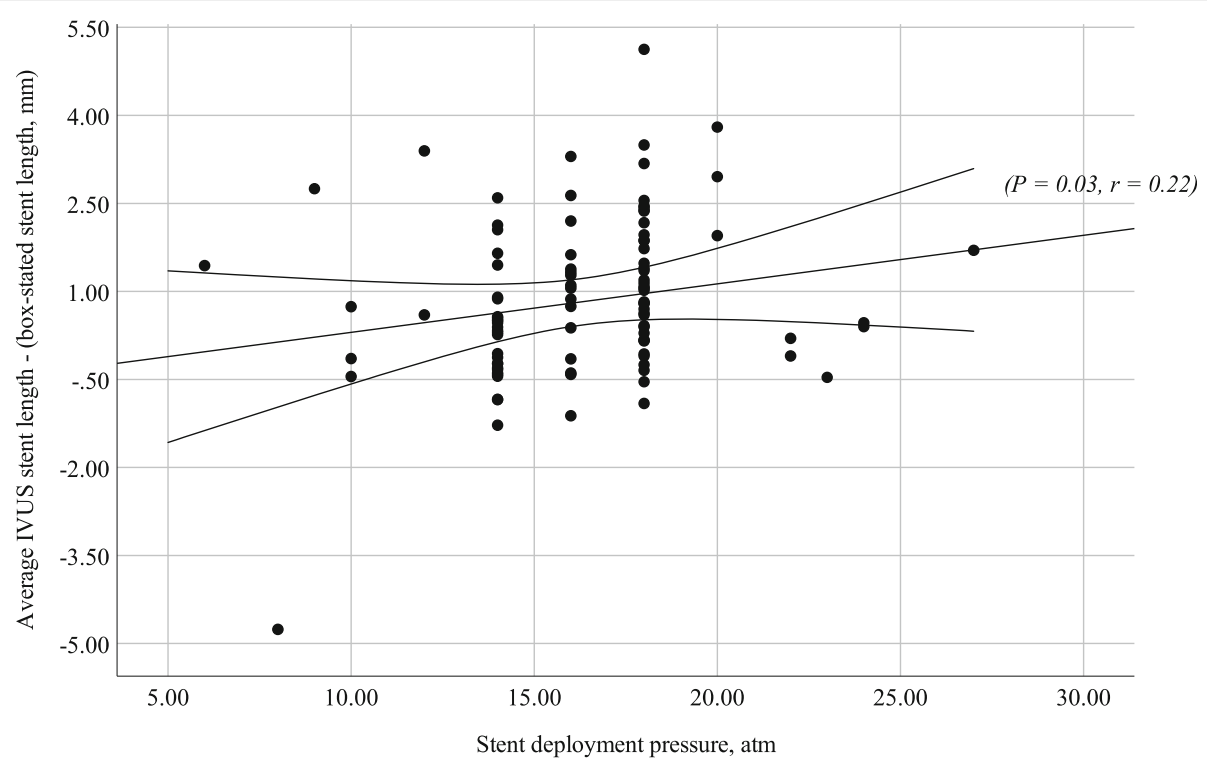

Fig. 2 Correlation between stent deployment pressure and difference of stent length. A significant direct relation between stent deployment pressure and difference in stent length

elongation because of less resistance encountered by the vessel wall. Lesion and edge plaque types regarding lipid-rich plaque, fibrous plaque, and calcific plaque are not a predictor of a difference in stent length in our study. Moreover, the site of calcification either superficial or deep is not a predictor too. The only important IVUS predictor is the plaquemedia area at both lesion and edge locations. The explanation of the relation between plaque and stent length is not a simple relation or effect as has been illustrated in a model study performed by Wei et al. [25]. They demonstrated how complex the interaction between stent-plaque-artery. In his model, stent length was affected by plaque eccentricity and plaque compositions regarding lipid pool, fibrous cap, and calcification. They demonstrated that stent expanded asymmetrically in the axial direction because of plaque eccentricity and stiffness of fibrous capsule and calcification zones. He showed that the minimal stent length was located at the stenosed

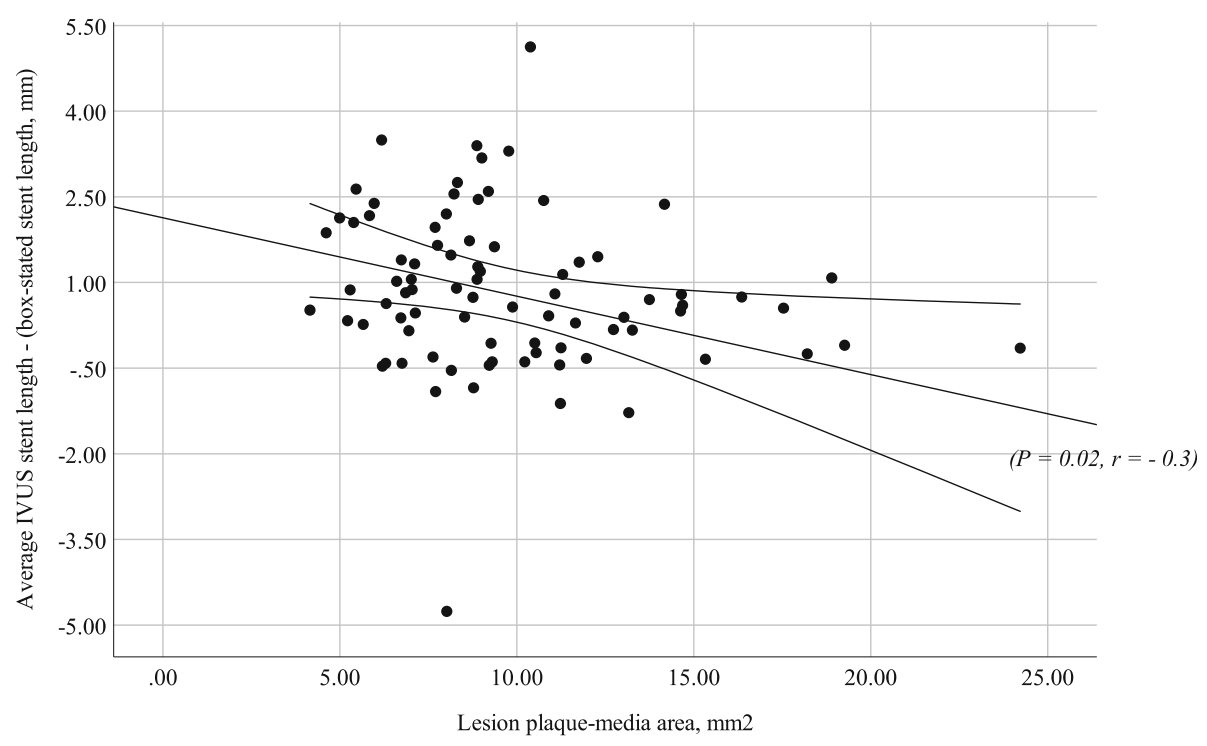

Fig. 3 Correlation between the plaque-media area and difference of stent length. A significant inverse relation between plaque-media area and difference in stent length 
side of the plaque while the maximum length at the opposite side, and the highest the complexed plaque, the greatest the stent foreshortening [25].

Another important factor predisposing to stent elongation rather than high-pressure post-dilatation, direction of post-dilatation, malapposition of stent edge, and less plaque-media area or stent-plaque-artery complex is the number of connectors between stent hoops as it affects longitudinal stent strength. Designs with 2 connectors such as Promus and Endeavor stents are more likely to elongate $[4,10,16]$ than those with more connectors such as Xience stent (3 connectors) and Cypher stent (6 connectors) $[4,16,23]$.

Stent elongation and shortening in this study preserve stent geometry; however, other forms of elongation and shortening distorting stent geometry may occur and are known as LSD. The incidence of LSD is low ranging from $0.1 \%$ [5] to $1.1 \%[9,10]$. It can cause acute stent thrombosis, numerically high target lesion failure on long-term outcomes [14], or even death [7]. Although it may influence any stent, Promus stent is more frequently encountered in clinical studies [8, 9, 11-13]. The most common sites are ostial and bifurcation lesions especially in the left main artery [10] and are caused mainly by mechanical insults such as catheter engagement and advancing and/or withdrawing of imaging catheters (IVUS, OCT), balloon, second stent, embolic protection devices, or guidewire. The most frequent pattern is strut wrinkling, overlapping, stretching, concertina, or excessive shortening $[6-8,10]$. It can be diagnosed by angiography, IVUS, OCT, and multislice computed tomography [26] and should be treated by further balloon dilatation and/or stenting.

IVUS is an important tool for the selection of stent length and assessment after stent deployment $[15,17$, 27]. Grayscale IVUS gives similar results to ECG-gated IVUS on measuring stent length [28]. More recently, OCT is used as an imaging modality before and after stenting. It can be used effectively to measure stent length [17] though stent length may be shorter in some studies [29, 30]. Other modalities such as multislice computed tomography $[26,31,32]$ and 3D quantitative coronary angiography (QCA) have also a good correlation with IVUS measurements [33].

\section{Study limitations}

The study has some limitations. It is not a prospective study. The study included a real-life daily work in the catheterization room, and it is not powered to compare between the different stent types. Some manufacturers mention foreshortening in a range of percentage only and not in length $(\mathrm{mm})$. The predicted calculated foreshortened length $(\mathrm{mm})$ was calculated by measuring the maximum percentage. Stents longer than $20 \mathrm{~mm}$ account for only $32 \%$ to avoid incorrect measurements. The number of stents is not large enough to calculate multivariate analysis of the difference of stent length for each stent diameter. Insurance grant affects the selection of stent type.

\section{Conclusions}

After deployment of coronary stents in real-life coronary lesions, most of the stents are longer than the manufacturer length. It is useful to assure full lesion coverage but avoid excessive stent elongation that may protrude into the main vessel such as the left main coronary artery. This elongation is related to dilatation pressure and plaque-media at the whole lesion segment and worth mentioning in manufacturer documents.

\section{Abbreviations \\ A-A length: Area-to-area stent length; BMS: Bare-metal stent; DES: Drug- eluting stent; ECG: Electrocardiogram; E-E length: Edge-to-edge stent length; $\mathrm{EEM}=\mathrm{VA}$ : External elastic membrane $=$ vessel area; IQR: Interquartile range; IVUS: Intravascular ultrasound study; LA: Lumen area; LSD: Longitudinal stent deformation; NIRS-IVUS: Near-infrared spectroscopy and IVUS; OCT: Optical coherence tomography; QCA: Quantitative coronary angiography}

\section{Acknowledgements}

Not applicable.

\section{Authors' contributions}

MA carried out all IVUS measurements of the study, made the objective, and wrote the manuscript.

MAE helped to draft the manuscript.

All authors read and approved the final manuscript.

\section{Funding}

The authors of this manuscript declare that they did not receive any funds for this project.

\section{Availability of data and materials}

The manuscript data is available on request to the corresponding author.

\section{Declarations}

The submitted article is an original article and has not been published before. The study was presented in part in ESC 2014, Barcelona, Spain (P 4520, from 30/08/2014 to 3/09/2014).

Ethics approval and consent to participate

Patients were included after the written consent was signed by the patients. The study was approved by the Ethics Committee of Faculty of Medicine, Assiut University with approval number IRB 00008718 , registered by the Office for Human Research Protection.

Consent for publication

Not applicable.

Competing interests

The authors declare that they have no competing interests.

Received: 26 May 2020 Accepted: 6 May 2021

Published online: 17 May 2021

\section{References}

1. de Ribamar Costa J Jr, Mintz GS, Carlier SG et al (2005) Intravascular ultrasonic assessment of stent diameters derived from manufacturer's compliance charts. Am J Cardiol 96(1):74-78. https://doi.org/10.1016/j.amjca rd.2005.02.049 
2. de Ribamar Costa J Jr, Mintz GS, Carlier SG et al (2007) Intravascular ultrasound assessment of drug-eluting stent expansion. Am Heart J 153(2): 297-303. https://doi.org/10.1016/j.ahj.2006.08.026

3. Dong P, Bezerra HG, Wilson DL, GU L (2018) Impact of calcium quantifications on stent expansions. J Biomech Eng doi:https://doi.org/1 0.1115/1.4042013, 141:2 0210101-0210108.

4. Ormiston JA, Webber B, Webster MW (2011) Stent longitudinal integrity bench insights into a clinical problem. JACC Cardiovasc Interv 4(12):13101317. https://doi.org/10.1016/j.jcin.2011.11.002

5. Williams PD, Mamas MA, Morgan KP, el-Omar M, Clarke B, Bainbridge A, Fath-Ordoubadi F, Fraser DG (2012) Longitudinal stent deformation: a retrospective analysis of frequency and mechanisms. Eurolntervention 8(2): 267-274. https://doi.org/10.4244/EIJV8I2A41

6. Vogt P, Eeckhout E, Stauffer JC, Goy JJ, Kappenberger L (1994) Stent shortening and elongation: pitfalls with the Wiktor coronary endoprosthesis. Catheter Cardiovasc Diagn 31(3):233-235. https://doi.org/10.1002/ccd.181 0310315

7. Chalet Y, Panes F, Chevalier B, Monassier JP, Spaulding C, Lancelin B, Elkouby A (1994) Should we avoid ostial implantations of Wiktor stents? Catheter Cardiovasc Diagn 32(4):376-379. https://doi.org/10.1002/ccd.181 0320419

8. Abdel-Wahab M, Sulimov DS, Kassner G et al (2012) Longitudinal deformation of contemporary coronary stents: an integrated analysis of clinical experience and observations from the bench. J Interv Cardiol 25(6): 576-585. https://doi.org/10.1111/j.1540-8183.2012.00765.x

9. von Birgelen C, Sen H, Lam MK, Danse PW, Jessurun GAJ, Hautvast RWM, van Houwelingen GK, Schramm AR, Gin RMTJ, Louwerenburg JW, de Man FHAF, Stoel MG, Löwik MM, Linssen GCM, Saïd SAM, Nienhuis MB, Verhorst PMJ, Basalus MWZ, Doggen CJM, Tandjung K (2014) Third-generation zotarolimus-eluting and everolimus-eluting stents in all-comer patients requiring a percutaneous coronary intervention (DUTCH PEERS): a randomised, single-blind, multicentre, non-inferiority trial. Lancet 383(9915): 413-423. https://doi.org/10.1016/S0140-6736(13)62037-1

10. Inaba S, Weisz G, Kobayashi N, Saito S, Dohi T, Dong L, Wang L, Moran JA, Rabbani LRE, Parikh MA, Leon MB, Moses JW, Mintz GS, Maehara A (2014) Prevalence and anatomical features of acute longitudinal stent deformation: an intravascular ultrasound study. Catheter Cardiovasc Interv 84(3):388-396. https://doi.org/10.1002/ccd.25411

11. Yamada R, Okura H, Kume T, Fukuhara K, Koyama T, Higa T, Neishi Y, Yoshida K, Uemura S (2017) Impact of stent platform on longitudinal stent deformation: an in vivo frequency domain optical coherence tomography study. Cardiovasc Interv Ther 32(3):199-205. https://doi.org/10.1007/s12928016-0403-3

12. Patil S, Setty N, Ramalingam R, Kharge J, Manjunath CN (2017) Coronary stent concertina in proximal left anterior descending artery: an unusual case. Interv Med Appl Sci 9(2):112-115. https://doi.org/10.1556/1646.9.201 7.2 .19

13. Panoulas VF, Demir OM, Ruparelia N, Malik I (2017) Longitudinal deformation of a third generation zotarolimus eluting stent: "the concertina returns!". World J Cardiol 9(1):60-64. https://doi.org/10.4330/wjc.v9.11.60

14. Rhee TM, Park KW, Lee JM, Lee MS, Jeon KH, Kang HJ, Koo BK, Rhew JY, Cha KS, Bae JH, Han KR, Park SH, Park WJ, Rha SW, Oh SK, Kwon HM, Seung KB, Ahn T, Kim SH, Kim HS (2017) Predictors and long-term clinical outcome of longitudinal stent deformation: insights from pooled analysis of Korean multicenter drug-eluting stent cohort. Circ Cardiovasc Interv 10(11):e005518. https://doi.org/10.1161/CIRCINTERVENTIONS.117.005518

15. Tanaka K, Carlier SG, Mintz GS, Sano K, Liu X, Fujii K, de Ribamar Costa J Jr, Lui J, Moses JW, Stone GW, Leon MB (2007) The accuracy of length measurements using different intravascular ultrasound motorized transducer pullback systems. Int J Cardiovasc Imaging 23(6):733-738. https://doi.org/1 0.1007/s10554-007-9216-X

16. Dvir D, Kitabata H, Barbash IM, Minha S', Badr S, Loh JP, Chen F, Torguson R, Waksman R (2014) In vivo evaluation of axial integrity of coronary stents using intravascular ultrasound: insights on longitudinal stent deformation. Catheter Cardiovasc Interv 84(3):397-405. https://doi.org/10.1002/ccd.25292

17. Räber L, Mintz GS, Koskinas KC, Johnson TW, Holm NR, Onuma Y, Radu MD, Joner M, Yu B, Jia H, Meneveau N, de la Torre Hernandez JM, Escaned J, Hill J, Prati F, Colombo A, di Mario C, Regar E, Capodanno D, Wijns W, Byrne RA, Guagliumi G, ESC Scientific Document Group, Alfonso F, Bhindi R, Ali Z, Carter R (2018) ESC Scientific Document Group. Clinical use of intracoronary imaging. Part 1: guidance and optimization of coronary interventions. An expert consensus document of the European Association of Percutaneous Cardiovascular Interventions. Eur Heart J 39(35):3281-3300. https://doi.org/1 0.1093/eurheartj/ehy285

18. Hanson ID, Goldstein JA, Dixon SR, Stone GW (2015) Comparison of coronary artery lesion length by NIRS-IVUS versus angiography alone. Coron Artery Dis 26(6):484-489. https://doi.org/10.1097/MCA.0000000000000263

19. Matsuda Y, Ashikaga T, Sasaoka T, Hatano Y, Umemoto T, Yamamoto T, Maejima Y, Hirao K (2018) Effectiveness of the proximal optimization technique for longitudinal stent elongation caused by post-balloon dilatation. J Interv Cardiol 31(5):624-631. https://doi.org/10.1111/joic.12543

20. Sumi T, Ishii H, Tanaka A, Suzuki S, Kojima H, Iwakawa N, Aoki T, Hirayama K, Mitsuda T, Harada K, Negishi Y, Ota T, Kada K, Murohara T (2018) Impact of post-dilatation on longitudinal stent elongation: an in vitro study. J Cardiol 71(5):464-470. https://doi.org/10.1016/j.jjcc.2017.11.003

21. Matsushita K, Arakawa K, Hibi K, Kimura K, Umemura S, Himeno H (2014) Longitudinal stent deformation elongating to left main trunk. Cardiovasc Interv Ther 29(3):247-251. https://doi.org/10.1007/s12928-013-0220-x

22. Yoshida H, Matsumura A (2014) Assessment of differences in degree of elongation between stents by coronary CT angiography. J Am Coll Cardiol 63(suppl 2):A-094. https://doi.org/10.1016/j.jacc.2014.02.563

23. Domei T, Amemiyaa K, Ito T et al (2013) Longitudinal drug eluting stent elongation phenomenon after high pressure additional post stent dilatation: insight from bench testing. Am J Cardiol 111 (suppl):25B. https://doi.org/10.1 016/j.amjcard.2013.01.066

24. Matsumura A (2013) Impact of longitudinal stent elongation during percutaneous coronary intervention. Am J Cardiol 111 (suppl):25B. https:// doi.org/10.1016/j.amjcard.2013.01.067

25. Wei L, Chen Q, Li Z (2019) Influences of plaque eccentricity and composition on the stent-plaque-artery interaction during stent implantation. Biomech Model Mechanobiol 18(1):45-56. https://doi.org/10.1 007/s10237-018-1066-z

26. Romaguera R, Roura G, Gomez-Lara J, Ferreiro JL, Gracida M, Teruel L, de Albert M, Ariza A, Gomez-Hospital JA, Cequier A (2014) Longitudinal deformation of drug-eluting stents: evaluation by multislice computed tomography. J Invasive Cardiol 26(4):161-166

27. Algowhary M, Taha S, Hasan-Ali H, Matsumura A (2019) In vivo measurement of stent length by using intravascular ultrasound. Egypt Heart J 71(1):32. https://doi.org/10.1186/s43044-019-0036-9

28. Kaple RK, Tsujita K, Maehara A, Mintz GS (2009) Accuracy of stent measurements using ECG-gated greyscale intravascular ultrasound images: a validation study. Ultrasound Med Biol 35(8):1265-1270. https://doi.org/10.1 016/j.ultrasmedbio.2009.02.003

29. Fujino Y, Bezerra HG, Attizzani GF, Wang W, Yamamoto H, Chamié D, Kanaya T, Mehanna E, Tahara S, Nakamura S, Costa MA (2013) Frequency-domain optical coherence tomography assessment of unprotected left main coronary artery disease-a comparison with intravascular ultrasound. Catheter Cardiovasc Interv 82(3):E173-E183. https://doi.org/10.1002/ccd.24843

30. Liu Y, Shimamura K, Kubo T, Tanaka A, Kitabata H, Ino Y, Tanimoto T, Shiono Y, Orii M, Yamano T, Yamaguchi T, Hirata K, Imanishi T, Akasaka T (2014) Comparison of longitudinal geometric measurement in human coronary arteries between frequency-domain optical coherence tomography and intravascular ultrasound. Int J Card Imaging 30(2):271-277. https://doi.org/1 0.1007/s 10554-013-0330-7

31. Kass M, Glover CA, Labinaz M, So DY, Chen L, Yam Y, Chow BJ (2010) Lesion characteristics and coronary stent selection with computed tomographic coronary angiography: a pilot investigation comparing CTA, QCA and IVUS. J Invasive Cardiol 22(7):328-334

32. Ciszewski M, Zalewska J, Pregowski J, Mintz GS, Kepka C, Kalinczuk L, Kruk M Jastrzebski J, Witkowski A (2013) Comparison of stent length reported by the stent's manufacturer to that determined by quantitative coronary angiography at the time of implantation versus that determined by coronary computed tomographic angiography at a later time. Am J Cardiol 111(8):1111-1116. https://doi.org/10.1016/..amjcard.2012.12.035

33. Tu S, Huang Z, Koning G, Cui K, Reiber JHC (2010) A novel threedimensional quantitative coronary angiography system: in-vivo comparison with intravascular ultrasound for assessing arterial segment length. Catheter Cardiovasc Interv 76(2):291-298. https://doi.org/10.1002/ccd.22502

\section{Publisher's Note}

Springer Nature remains neutral with regard to jurisdictional claims in published maps and institutional affiliations. 